\title{
Kill a Pinta goat a day ...
}

Science and conservation in the

Galapagos Archipelago must swim against a fast running tide of tourism and goats. David Davies looks at the way in which the Ecuadorian Government and the Charles Darwin Foundation are trying to maintain the islands.

"I Found long ago that I cannot live happily without the Galapagos Islands; even if $I$ am not there I need to know that they exist undestroyed by goats or men ..." So wrote Peter Kramer, retiring director of the Charles Darwin Station on Santa Cruz in the Galapagos Islands in December 1973.

The Galapagos Archipelago is on the equator about 1,400 kilometres off the Ecuadorian coast. Darwin was there for 35 days in 1835 , and was deeply influenced by what he saw. His field notes were dominantly geological; he was struck by the youthful volcanic nature of the rocks. It was however, the biological scene which was ultimately to have most impact on himgiant tortoises, finches (Darwin's finches) whose bills were "modified for different ends", marine iguanas, flightless cormorants and many others. By the time Darwin was writing Origin of Species he had absorbed much else and the effect of his stay in the Galapagos is less obvious, but in his early evolutionary writings the significance of islands is crystal clear; in 1842 he wrote on the back of a notepad "islands are the nursery of new species".

$\mathrm{He}$ was not the only visitor to the Galapagos. In the nineteenth century whalers would put in on their long journey from the Pacific to the American East Coast round Cape Horn, and would collect a giant tortoise to keep in the hold of the ship for later consumption. Many other ships also put in to the Galapagos, caring nothing about what species they brought in. One such import about seventy years ago was the Norwegian black rat which had such a grip on Pinzon, for example, that by 1965 no tortoises younger than thirty could be found; all tortoise hatchlings were being killed by rats. Other feral animals such as the pig have also wrought havoc on the tortoise population of various islands by eating the eggs. But the most dramatic and visible introduction has been the goat.
The local population has been in the habit of depositing goats on the more remote islands to ensure a food supply for fishing expeditions. Thus in 1958, a male and two females were left on Pinta. By 1968 the number had reached 4,000 to 5,000 and in 1971 the estimate was "not below 20,000". Hardly surprisingly, species of plants unique to the archipelago are threatened by this population on Pinta and elsewhere.

Not all the impact on the Galapagan environment has come from man's works. There are many historically active volcanoes in the west of the archipelago, and in 1968 the caldera collapse of Fernandina was the world's largest collapse in seventy years. In addition latitudinal oscillations of the Oceanic Equatorial Counter Current (the 'El Niño' phenomenon) lead to long term fluctuations in rainfall and have striking effects on the life of the islands. The most recent threat, however, has been man himself, as resident and tourist.

The population of the islands was less than 1,000 in 1960; now it is more than 4,000. Santa Cruz and San Cristobal have the most inhabitants whilst some islands, particularly the active volcanoes, are prudently uninhabited. Many of the inhabitants are farmers but an increasing number are needed

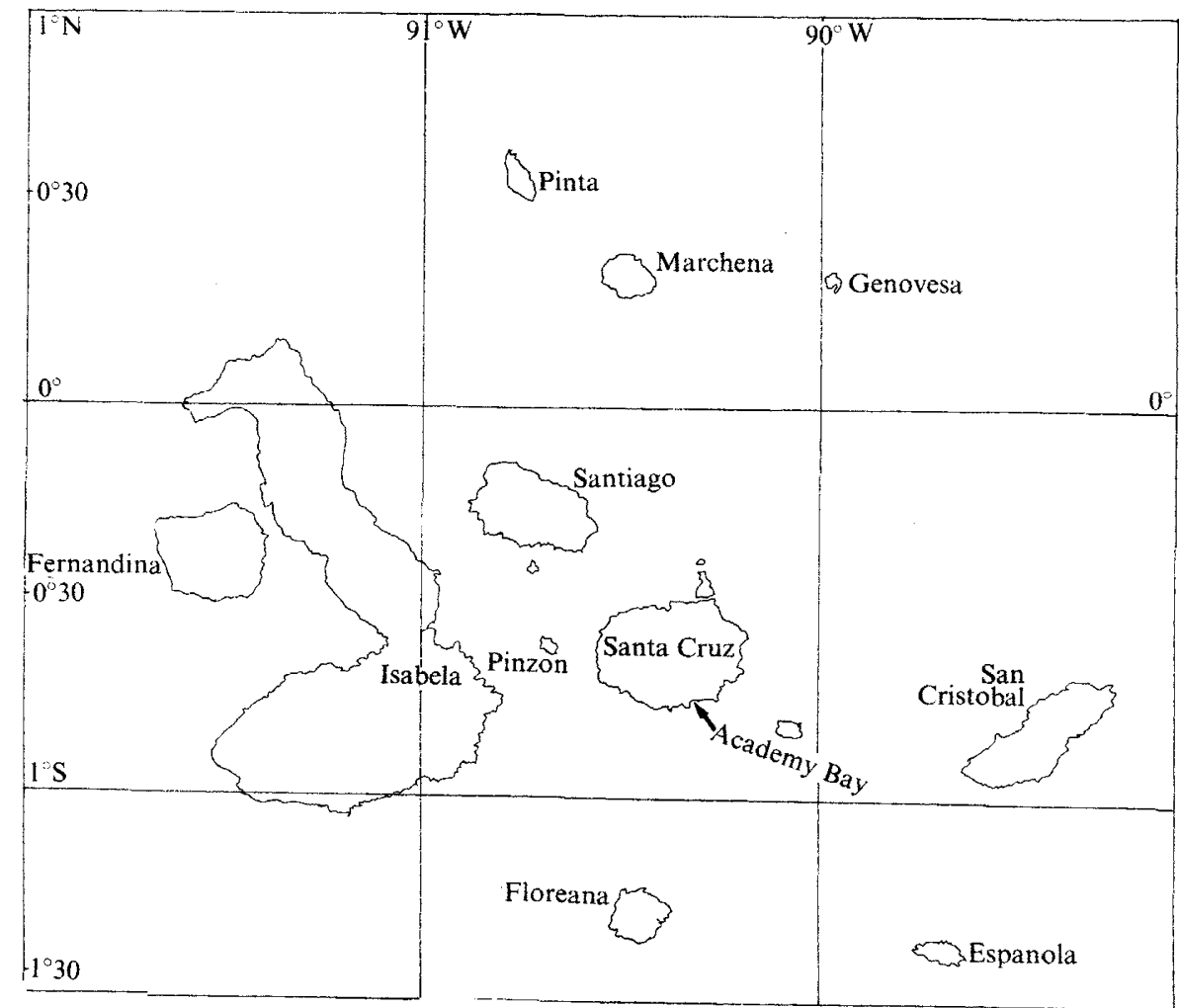

to service a tourist industry which now provides for several thousand annually compared with 200 in 1969. Much of this tourism has been stimulated by the natural environment of the Galapagos and has been appropriately careful, but a growing number of private yachts visit the island on Pacific cruises and they are causing serious problems. As one scientist put it, "man has now replaced goats as the greatest threat".

The conservation issue is not simple. Although biologists would agree that there is an obvious case for the strictest of measures to preserve the islands intact, they are also the home of many Ecuadorians. In addition they occupy a strategic naval position. In two World Wars it was "he who holds the Galapagos holds the Panama Canal". There is thus a strong naval presence and in the past has even been some suspicion by the military that scientific operations have had more sinister overtones. There is thus a delicate diplomatic balance necessary in order that residents, military, tourists and nature coexist.

Ecuador has had a formal interest in Galapagan conservation since 1934 when legislation was enacted to ban the export of protected animals and the import of domestic ones. Nature reserves were also established, but 
Tortoise house on Santa Cruz: keeping the rats at bay

the legislation was ineffective as there was no organisation to enforce them. An American effort to set up a scientific station in 1941 was shelved because of the war, and it was not until 1959 that a Charles Darwin Foundation for the Galapagos Isles was formed in Belgium with the aim of constructing a research station on Santa Cruz. Also in 1959 Ecuador declared the whole archipelago (save four small inhabited areas) a national park. The Galapagos National Park Service now has nine officials and wardens and will grow with the revenue from a levy on tourists. A much talkedabout event in 1971 was the removal and resettlement of fifteen families living illegally in park territory. This was seen as unequivocal evidence that the government would even act against its own subjects in maintenance of the park. In addition poaching has been cut down and undesirable tourist schemes stopped. The goats and pigs are under control in the smaller islands although there is an enormous amount of work still to be done on the larger islands. Most important, there is a close collaborative arrangement with the Darwin Foundation. A concern voiced by the Forestry Service, however, is that it will not be possible much longer for Galapaguenos to live with a scientific research station and a tourist industry which constrict their freedom without sharing the income.

The Charles Darwin Research Station at Academy Bay has been the staging post for research since the early 1960s. UNESCO has paid for the director (the present one is Craig Macfarland, whose primary scientific interest is the tortoise). Building of a laboratory, a house for the director and accommodation for visitors was finished by 1963. Once the extent of the depredations of the rats on Pinzon's tortoises had been discovered and some success achieved with rearing at the station, the San Diego Zoological Society helped provide a special building (see picture) for tortoise rearing. A few other buildings are now also in the complex. The staff comprises, in addition to the director, one or two additional scientists and maintenance and service workers. A yacht, Beagle III is also operated. It would be foolish to pretend, however, that the station is a great social and scientific centre. It is generally regarded by visitors as adequate in basic facilities for support-

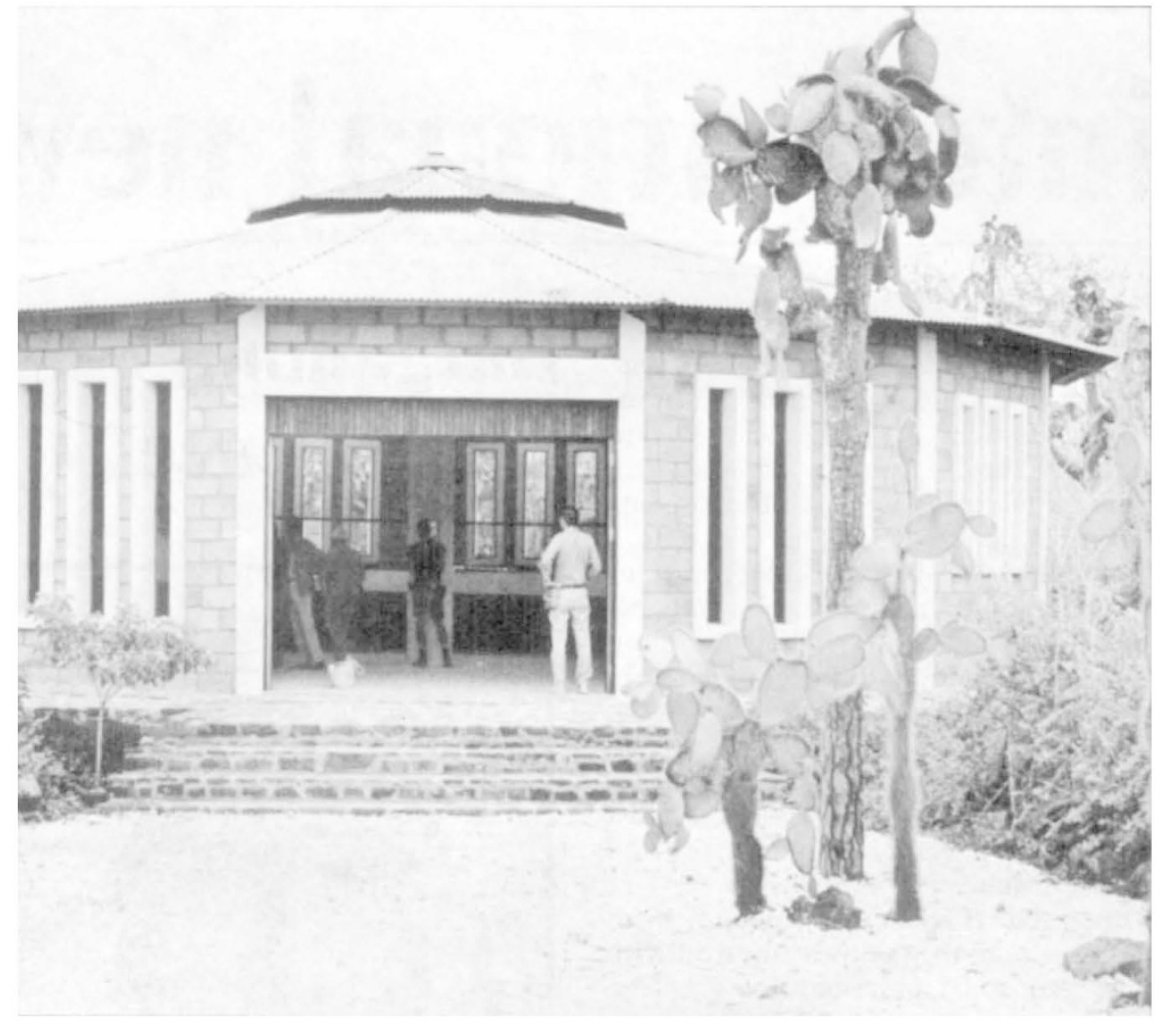

ing up to twelve visitors, but several scientists speak of the depressing environment. "Like an unmanned youth hostel" was one remark. "The station has to spend much of its income shooting goats and standing guard" was another. It gets just one journal-a complimentary Nature.

Up till now the Charles Darwin Foundation has operated entirely on a voluntary basis. It has officers both in Europe and America all of whom give their services free; several institutions either pay for a research table or donate funds but UNESCO support for the director will end this summer. The World Wildlife Fund has been funnelling some funds to the station. The Smithsonian in Washington provides secretarial assistance and the services of one of its staff, Tom Simkin, as Secretary for the Americas. And many individual friends of the Galapagos donate. At least $\$ 100,000$ is needed annually just to keep the station alive; much more for it to pursue the more stimulating and imaginative programmes it would wish to do, in particular the education of young Ecuadorians. It is going to be increasingly difficult for a research station to exist without providing tangible educational benefits to Ecuador. At present there are programmes for Galapagan residents and teachers, wardens and students from the mainland, but there is a widespread feeling that much more needs to be done to draw the Ecuadorian scientific community into the station's activities, and this means being able to provide for university students and give them a taste of biological research-something that they will otherwise find difficult to get without emigrating.

The question that now has to be asked is whether the Charles Darwin Foundation can continue its funding, and hence its programmes, in a piecemeal fashion dependent on the goodwill and hard work of unpaid officers. Peter Kramer was particularly adept at fund raising and last year organised a benefit cruise to the Galapagos which brought in $\$ 50,000$. But this year's attempted repeat failed to get the patronage, the cruise was cancelled and the deposit lost. "It's partly the change in economic climate," says Simkin, "but to be honest, we just didn't hustle enough; we are full-time scientists inexperienced in the art of persuading". The attractions of an organisation with no overheads at all have soon to be weighed against the need for a continual expansion of scientific, conservation and education programmes which necessarily requires some professionalism on the financial side, particularly since the director's salary now has to be paid by the foundation. There is a divergence between Europe and the United States in approach. The Europeans on the foundation are more prepared to take financial setbacks and consequent delays phlegmatically whereas the Americans seem to be increasingly concerned that delay and a continued environment of poverty for the director and visiting scientists could lead to permanent loss. 